\title{
A verification of the ITTC/ISO speed/power trials analysis
}

\author{
Gerhard Strasser • Ken Takagi · Sofia Werner • \\ Uwe Hollenbach · Taichi Tanaka - Kotaku Yamamoto • \\ Kazuyoshi Hirota
}

Received: 2 December 2014 / Accepted: 2 January 2015/Published online: 13 January 2015

(C) The Author(s) 2015. This article is published with open access at Springerlink.com

\begin{abstract}
Speed and power (S/P) trials are most important to guarantee the ship's propulsive performance. However, it was pointed out that the existing procedures often give a good guideline, but are not specific and can introduce inconsistent results. Recently, ITTC and ISO have improved their $\mathrm{S} / \mathrm{P}$ trials procedures and harmonized the two procedures. During the harmonization process, we have verified the 'Mean of Means' (MoM) method and the 'Iterative' method which are used as the current correction methods and the 'Direct Power Method' and the 'Extended Power Method' which are applied for the evaluation of the acquired data. The results of verification are presented in this paper. The results show that using the 'MoM' method for each power setting, two double runs should be made to keep the accuracy of S/P trials, and the 'Iterative' method leads to less errors in average of the tested cases when $1+2+2$ double runs are used in the 'MoM' method, although the methods are equally adequate if the time periods between the runs are short enough. In specific cases, e.g. in case of large speed range and/or humps and hollows within the speed-power curve, the 'MoM' method has advantages over the 'Iterative' method. In case of current time history deviating from the assumed parabolic/ sinusoidal trend and the change of the current within the time span of two double runs is very high, neither of the methods are applicable. Summarizing the results, the 'Iterative' method is fully compatible with the simple 'Direct Power Method'.
\end{abstract}

G. Strasser · K. Takagi $(\bowtie) \cdot$ S. Werner · U. Hollenbach ·

T. Tanaka $\cdot$ K. Yamamoto $\cdot$ K. Hirota

The University of Tokyo, Tokyo, Japan

e-mail: takagi@k.u-tokyo.ac.jp
Keywords Speed/power trials - Propulsive performance · Current correction · Guideline

\section{Introduction}

Speed and power (S/P) trials are conducted to establish the ship's performance at design or other stipulated draught and trim under no wind, no wave and no current condition. Although S/P trials are most important to guarantee the ship's propulsive performance, there was no internationally recognized standard prior to ISO15016:2002 [1]. Many shipyards developed their own procedures based on their experience and recommendations given in scientific literature. This literature is published by academic communities. For example, International Towing Tank Conference (ITTC) reported 'ITTC Guide for Measured-Mile Trials' in 1969 [2] and updated it in 1996 [3]. The Society of Naval Architects and Marine Engineers (SNAME) produced 'Code for Sea Trials' in 1978 [4]. This was later superseded in 1989 [5]. The British Ship Research Association (BSRA) issued 'BSRA standard method of Speed Trial Analysis' in 1978 [6].

The sea trial analysis (STA)-JIP [7] pointed out that the existing procedures often give a good guideline, but are not specific and can introduce inconsistent results, and proposed trial procedures based on two practices outlined by the ISO15016:2002 and the recommendations to the 22nd and 23rd ITTC [8,9]. STA-JIP practice gives a practical overview of the minimum requirements that should be met to obtain reliable and single speed trial results.

On the other hand, in relation to the verification of the Energy Efficiency Design Index (EEDI), Norway proposed IMO to request a revision of ISO15016:2002 at the 62nd Marine Environmental Committee (MEPC) of IMO [10]. 
The 63rd MEPC [11] had noted that ITTC would develop a standard for the assessment of the speed and power performance by analysis of speed trial data in time. Accordingly, ITTC submitted its new recommended procedure for speed/power trials to the 64th MEPC [12]. This recommended procedure improves the ISO 15016:2002 and takes into account the improvements by the STA-JIP method. The part I of the ITTC procedure (Preparation and Conduct of Speed/Power Trials) was also submitted to the 65th MEPC [13]. At the same time, the MEPC committee requested ISO to revise, as soon as possible, ISO 15016:2002, taking into account the new recommended procedures by ITTC [14].

According to this request, ITTC and ISO started to harmonize the two procedures. During the harmonization process, we have verified the 'Mean of Means' (MoM) method and the 'Iterative' method which are used as the current correction methods and the 'Direct Power Method' and the 'Extended Power Method' which are applied for the evaluation of the acquired data. The aims of this paper are to show the results of the verification and to propose some recommendations on $\mathrm{S} / \mathrm{P}$ trials procedures.

It is noted that, although the newly developed ISO 15016:2015 [15] mentions other corrections such as the resistance increase due to wind and waves, effects of the water temperature and density, the water depth and so on, only the current correction is in the limelight of this paper, because the current correction is vital in the S/P trials as long as we have no reliable tool for measuring the ship's speed through the water.

\section{Current correction method}

\subsection{Conduct of the trial}

It is stated in ISO 15016:2015 [15] that the S/P trial runs are conducted over the same ground area. Each trial run is commenced and completed at the same place. Modified Williamson turns or similar types of maneuvre are executed between each run to return the ship to the reciprocal heading on, or parallel to, the trial baseline. The run duration should be the same for all speed runs with a minimum of $10 \mathrm{~min}$. The speed runs for the same power setting should be evenly distributed in time.

To determine the S/P curve, a certain number of double runs, which are defined as two consecutive speed runs at the same power setting on reciprocal headings, are required. The number of runs is determined to keep the accuracy of current correction. In the case of the 'Iterative' method, a minimum of four double runs at three different power settings is required for the first ship of a ship series. These power settings should be adequately distributed within the power range of $65 \%$ maximum continuous rating (MCR) and $100 \% \mathrm{MCR}$ and comprise at least two double runs around EEDI/Contract power, one double run below EEDI/Contract power and one double run above EEDI/Contract power.

If the MoM method is preferred, a minimum of six double runs at three different power settings is required. These power settings comprise at least two double runs around EEDI/Contract power, two double runs below EEDI/Contract power and two double runs above EEDI/ Contract power.

\section{2 'Iterative' method}

In the 'Iterative' method, the current speed is assumed to vary with, inter alia, the semidiurnal period. A current curve is determined as a function of time as follows:

$$
V_{\mathrm{C}}=V_{\mathrm{C}, \mathrm{C}} \cos \left(\frac{2 \pi}{T_{\mathrm{C}}} t\right)+V_{\mathrm{C}, \mathrm{S}} \sin \left(\frac{2 \pi}{T_{\mathrm{C}}} t\right)+V_{\mathrm{C}, \mathrm{T}} t+V_{\mathrm{C}, 0}
$$

where $V_{\mathrm{C}}$ is the current speed, $T_{\mathrm{C}}$ the period of variation of current speed, $t$ is the time for each run, and unknown factors $V_{\mathrm{C}, \mathrm{C}}, V_{\mathrm{C}, \mathrm{S}}, V_{\mathrm{C}, \mathrm{T}}$ and $V_{\mathrm{C}, 0}$.

The most dominant period is the lunar semidiurnal period of 0.51753 days ( $12 \mathrm{~h}, 25 \mathrm{~min}$ and $12 \mathrm{~s}$ ).

The ship's speed through the water $V_{\mathrm{S}}$ is derived from a regression curve (2.2) which represents the relationship between the ship's speed through the water and its power corrected which is defined as

$P\left(V_{\mathrm{S}}\right)=a+b V_{\mathrm{S}}^{q}$

where $P\left(V_{\mathrm{S}}\right)$ is the regression curve and unknown factors $a$, $b$ and $q$.

The initial value of $V_{\mathrm{S}}$ is taken as the average of the measured ship's speeds $V_{G}^{\prime}$ of a double run. As a first approximation of the regression curve representing the relationship between ship's speed and power, a mean curve is derived by determining the unknown factors, $a, b$ and $q$ of formula (2.2) by fitting the formula (2.2) to combinations of the initial value of $V_{\mathrm{S}}$ and averaged acquired power $P^{\prime}$ id by the 'least squares' method. The acquired power $P^{\prime}$ id is explained in Sect. 3 .

The current speed at the time for each run $V_{C}^{\prime}$ is calculated by subtracting the updated ship's speed through the water $V_{\mathrm{S}}$ from the measured ship's speed over the ground $V_{\mathrm{G}}$.

$V_{\mathrm{C}}^{\prime}=V_{\mathrm{G}}-V_{\mathrm{S}}$

A current curve is obtained by determining the unknown factors $V_{\mathrm{C}, \mathrm{C}}, V_{\mathrm{C}, \mathrm{S}}, V_{\mathrm{C}, \mathrm{T}}$ and $V_{\mathrm{C}, 0}$ of formula (2.1) by fitting the formula (2.1) to the combinations of time and current speed obtained from formula (2.3) by the 'least squares' 
method. The current speed on the current curve at the time for each run $V_{\mathrm{C}}$ is calculated from the formula (2.1) with the coefficients obtained as described above, and $V_{\mathrm{C}}$ is used as the updated current speed.

The ship's speed, corrected for current $V_{\text {S }}^{\prime}$, is calculated by subtracting the updated current speed $V_{\mathrm{C}}$ from the measured ship's speed over the ground $V_{\mathrm{G}}$.

$V_{\mathrm{S}}^{\prime}=V_{\mathrm{G}}-V_{\mathrm{C}}$

The updated regression curve representing the relationship between ship's speed and power is obtained by determining new factors of formula (2.2) by fitting the formula (2.2) to the combination of ship's speed obtained from formula (2.4) and corrected power by the 'least squares' method again.

The ship's speed through the water at the corrected power for each run $V_{\mathrm{S}}$ is recalculated as the updated one from the formula (2.2). These processes are then repeated until $\sum\left(P\left(V_{\mathrm{S}}^{\prime}\right)_{i}-P_{\mathrm{id} i}\right)^{2}$ is converged.

\section{3 'Mean of means' method}

Based on the assumption that for a given power setting, the current speed varies parabolically, the influence of current is accounted for by applying the MoM method for each set of runs with the same power setting.

If the current speed varies parabolically, a current curve is defined as a quadratic function of the time.

$V_{\mathrm{C}}=V_{\mathrm{C}, 2} t^{2}-V_{\mathrm{C}, 1} t+V_{\mathrm{C}, 0}$

where $V_{\mathrm{C}, 0}, V_{\mathrm{C}, 1}$ and $V_{\mathrm{C}, 2}$ are unknown factors.

If two double runs, i.e. four runs, are carried out, the MoM method can be used, and the following formula is derived to account for the current effect.

$V_{\mathrm{S}}=\frac{V_{\mathrm{G} 1}+3 V_{\mathrm{G} 2}+3 V_{\mathrm{G} 3}+V_{\mathrm{G} 4}}{8}$

where $V_{\mathrm{G} 1}$ is the measured ship's speed over the ground on the first of four runs, $V_{\mathrm{G} 2}$ the measured ship's speed over the ground on the second of four runs, $V_{\mathrm{G} 3}$ the measured ship's speed over the ground on the third of four runs, and $V_{\mathrm{G} 4}$ is the measured ship's speed over the ground on the fourth of four runs.

It is noted that an equal time interval between each run is assumed.

\section{Evaluation of acquired data}

\subsection{Direct power method}

To derive the S/P performance of the ship from the measured speed over the ground $V_{\mathrm{G}}$, power $P_{\mathrm{ms}}$ and propeller shaft speed $n_{\mathrm{ms}}$, the 'Direct Power Method' is used. The relationship between delivered power in the trial condition $P_{\mathrm{Dms}}$ and measured power is described in the following formula:

$P_{\mathrm{Dms}}=P_{\mathrm{Sms}} \cdot \eta_{\mathrm{S}}$

where $P_{\mathrm{Sms}}$ is the measured shaft power and $\eta_{\mathrm{S}}$ is the shaft efficiency.

In this method, the delivered power $P_{\mathrm{Dms}}$ is directly corrected with the power increase $\Delta P$ due to resistance increase $\Delta R$ in the trial condition.

$P_{\text {Did }}=P_{\text {Dms }}-\Delta P$

where $P_{\text {Did }}$ is the delivered power in the ideal condition and $\Delta P$ is the required correction for power.

The required correction for power $\Delta P$ is calculated by the following formula:

$\Delta P=\frac{\Delta R V_{\mathrm{S}}}{\eta_{\text {Did }}}+P_{\text {Dms }}\left(1-\frac{\eta_{\text {Dms }}}{\eta_{\text {Did }}}\right)$

where $\Delta R$ is the total resistance increase, $\eta_{\text {Dms }}$ the propulsive efficiency coefficient in the trial condition and $\eta_{\text {Did }}$ is the propulsive efficiency coefficient in the ideal condition.

The propulsive efficiency coefficient in the ideal condition $\eta_{\text {Did }}$ is obtained from standard towing tank tests and interpolated for the speed $V_{\mathrm{S}}$. The effect of resistance increase on the propeller loading and thus on the propulsive efficiency coefficient $\eta_{\text {Dms }}$ is derived considering the load variation effect. It is noted that the ideal condition means no wind, no waves, no current, deep water and standard temperature and density.

The propulsive efficiency is assumed to vary linearly with the added resistance according to:

$\frac{\eta_{\text {Dms }}}{\eta_{\text {Did }}}=\xi_{P} \frac{\Delta R}{R_{\text {id }}}+1$

where $\xi_{P}$ is a coefficient derived from the load variation test and $R_{\text {id }}$ is the resistance in the ideal condition.

This leads to $P_{\text {Did }}$ as follows under the condition $\left(P_{\text {Dms }}-\frac{\Delta R V_{\mathrm{S}}}{\eta_{\text {Did }}}>0\right)$

$P_{\text {Did }}=\frac{1}{2}\left(P_{\text {Dms }}-\frac{\Delta R V_{\mathrm{S}}}{\eta_{\text {Did }}}+\sqrt{\left(P_{\text {Dms }}-\frac{\Delta R V_{\mathrm{S}}}{\eta_{\text {Did }}}\right)^{2}+4 P_{\text {Dms }} \frac{\Delta R V_{\mathrm{S}}}{\eta_{\text {Did }}} \xi_{P}}\right)$

It is noted that the derivation of load variation coefficients is found in ISO15016:2015 [15].

\subsection{Extended power method}

Since the 'Direct Power Method' shown in Sect. 3.1 does not give any information on the full-scale wake fraction which is essential to know the physics of full-scale ship 
propulsion, the following procedure is described in Annex $\mathrm{K}$ of ISO15016:2015 [15] to obtain the full-scale wake fraction as well as related intermediate information such as the load factor, propeller efficiency and so on.

The propulsive efficiency coefficient $\eta_{\mathrm{D}}$ is generally calculated using the propeller open water efficiency $\eta_{\mathrm{O}}$ (which is assumed to be known here also as in the direct power method) and self-propulsion factors $\eta_{\mathrm{R}}, t$ and $w_{\mathrm{S}}$ as

$\eta_{\mathrm{D}}=\eta_{\mathrm{O}} \eta_{\mathrm{R}} \frac{1-t}{1-w_{\mathrm{S}}}$

where $\eta_{\mathrm{R}}$ is the relative rotative efficiency, $t$ the thrust deduction factor and $w_{\mathrm{S}}$ is the full-scale wake fraction.

Each self-propulsion factor for the trial condition is obtained by adding the deviation of each factor between the trial and the ideal condition. The deviations are described as functions of $\Delta R / R_{\text {id }}$ which is obtained from the results of the self-propulsion test with load variation effect.

$\eta_{\mathrm{Rms}}=\eta_{\mathrm{Rid}}+\Delta \eta_{\mathrm{R}}\left(\Delta R / R_{\mathrm{id}}\right)$,

$t_{\mathrm{ms}}=t_{\mathrm{id}}+\Delta t\left(\Delta R / R_{\mathrm{id}}\right)$,

$w_{\mathrm{Mms}}=w_{\mathrm{Mid}}+\Delta w_{\mathrm{M}}\left(\Delta R / R_{\mathrm{id}}\right)$

where $\eta_{\mathrm{Rms}}$ is the relative rotative efficiency in the trial condition, $t_{\mathrm{ms}}$ the thrust deduction factor in the trial condition, $w_{\mathrm{Mms}}$ the model wake fraction in the trial condition, $\eta_{\text {Rid }}$ the relative rotative efficiency in the ideal condition, $t_{\text {id }}$ the thrust deduction factor in the ideal condition, $w_{\text {Mid }}$ the model wake fraction in the ideal condition, $\Delta \eta_{\mathrm{R}}$ the deviation of relative rotative efficiency, $\Delta t$ the deviation of thrust deduction factor and $\Delta w_{\mathrm{M}}$ is the deviation of wake fraction.

On the other hand, the thrust coefficient, the torque coefficient and the load factor of a propeller (propeller open characteristics) are described by the following formulae.

$K_{T}=a_{T} J^{2}+b_{T} J+c_{T}$,

$K_{Q}=a_{Q} J^{2}+b_{Q} J+c_{Q}$,

$\tau_{\mathrm{P}}=a_{T}+b_{T} / J+c_{T} / J^{2}$

where $K_{T}$ is the thrust coefficient; $K_{Q}$ the torque coefficient; $\tau_{\mathrm{P}}$ the load factor equal to $K_{T} / J^{2} ; J$ the propeller advance coefficient; $a_{T}, b_{T}$ and $c_{T}$ the factors for the thrust coefficient curve; and $a_{Q}, b_{Q}$ and $c_{Q}$ are the factors for the torque coefficient curve.

If we know the self-propulsion factors in the trial condition $\eta_{\mathrm{Rms}}, t_{\mathrm{ms}}$ and $w_{\mathrm{Mms}} \eta_{\mathrm{Rm}}$ and the ship's speed through the water $V_{\mathrm{S}}$, the torque coefficient in the trial condition $K_{\mathrm{Qms}}$ is calculated as

$K_{Q \mathrm{~ms}}=\frac{P_{\mathrm{Dms}}}{2 \pi \rho_{\mathrm{S}} n_{\mathrm{ms}}^{3} D^{5}} \eta_{\mathrm{Rms}}$ where $\rho_{\mathrm{S}}$ is the water density, $n_{\mathrm{ms}}$ the measured propeller shaft speed and $D$ is the propeller diameter.The propeller advance coefficient $J_{\mathrm{ms}}$ is determined by using the torque coefficient $K_{Q \mathrm{~ms}}$.

$J_{\mathrm{ms}}=\frac{-b_{Q}-\sqrt{b_{Q}^{2}-4 a_{Q}\left(c_{Q}-K_{Q \mathrm{~ms}}\right)}}{2 a_{Q}}$.

The thrust coefficient in the trial condition $K_{T \mathrm{~ms}}$ is obtained by the formula (3.10) using the propeller advance coefficient in the trial condition $J_{\mathrm{ms}}$, and the propeller efficiency in the trial condition $\eta_{\text {Oms }}$ is obtained as

$\eta_{\mathrm{Oms}}=\frac{J_{\mathrm{ms}}}{2 \pi} \frac{K_{T \mathrm{~ms}}}{K_{Q m s}}$.

The load factor in the trial condition $\tau_{\mathrm{Pms}}$ is obtained as

$\tau_{\mathrm{Pms}}=\frac{K_{T \mathrm{~ms}}}{J_{\mathrm{ms}}^{2}}$.

The full-scale wake fraction in the trial condition $w_{\mathrm{Sms}}$ is obtained as

$1-w_{\mathrm{Sms}}=\frac{V_{\mathrm{A}}}{V_{\mathrm{S}}}$

where $V_{\mathrm{S}}$ is the ship's speed through the water and the speed of flow into propeller $V_{\mathrm{A}}$ is calculated as

$V_{\mathrm{A}}=J_{\mathrm{ms}} n_{\mathrm{ms}} D$.

The total resistance in the trial condition $R_{\mathrm{ms}}$ is also estimated using the load factor in the trial condition $\tau_{\mathrm{Pms}}$

$R_{\mathrm{ms}}=\tau_{\mathrm{Pms}}\left(1-t_{\mathrm{ms}}\right)\left(1-w_{\mathrm{Sms}}\right)^{2} \rho_{\mathrm{S}} V_{\mathrm{S}}^{2} D^{2}$.

The total resistance in the ideal condition $R_{\mathrm{id}}$ is obtained by subtracting the resistance increase $\Delta R$ from the total resistance in the trial condition $R_{\mathrm{ms}}$ as

$R_{\text {id }}=R_{\mathrm{ms}}-\Delta R$.

The full-scale wake fraction in the ideal condition $w_{\text {Sid }}$ is calculated by the following formula using the model wake fraction in the ideal condition $w_{\text {Mid }}$.

$1-w_{\text {Sid }}=\left(1-w_{\text {Mid }}\right) e_{\mathrm{i}}$

where the scale correlation factor of wake fraction $e_{\mathrm{i}}$ is obtained using the full-scale and model wake fractions in the trial conditions as

$e_{\mathrm{i}}=\frac{1-w_{\mathrm{Sms}}}{1-w_{\mathrm{Mms}}}$.

The load factor in the ideal condition $\tau_{\text {Pid }}$ is calculated by the following formula.

$\tau_{\text {Pid }}=\frac{R_{\text {id }}}{\left(1-t_{\text {id }}\right)\left(1-w_{\text {Sid }}\right)^{2} \rho_{\mathrm{S}} V_{\mathrm{S}}^{2} D^{2}}$. 
The propeller advance coefficient in the ideal condition $J_{\text {id }}$ is determined using the load factor $\tau_{\text {Pid }}$ obtained from formula (3.23).

$J_{\text {id }}=\frac{-b_{T}-\sqrt{b_{T}^{2}-4\left(a_{T}-\tau_{\text {Pid }}\right) c_{T}}}{2\left(a_{T}-\tau_{\text {Pid }}\right)}$

The thrust coefficient in the ideal condition $K_{T \mathrm{id}}$ and the torque coefficient $K_{Q \text { id }}$ are obtained by the formulae (3.10) and (3.11), respectively, using the propeller advance coefficient $J_{\text {id }}$. Thus, the propeller efficiency in the ideal condition $\eta_{\text {Oid }}$ is calculated as

$\eta_{\text {Oid }}=\frac{J_{\text {id }}}{2 \pi} \frac{K_{T \text { id }}}{K_{Q \text { id }}}$.

Finally, the corrected propeller shaft speed in the ideal condition $n_{\text {id }}$ is derived from the following equation.

$n_{\mathrm{id}}=\frac{V_{\mathrm{S}}\left(1-w_{\mathrm{Sid}}\right)}{J_{\mathrm{id}} D}$.

It is noted that the value of $V_{\mathrm{S}}$, and thus the values of $\eta_{\text {Rid }}$, $t_{\mathrm{id}}$ and $w_{\text {Mid }}$ are not known before we know the current velocity $V_{\mathrm{C}}$. Additionally, the value of $\Delta R / R_{\mathrm{id}}$, and thus the values of $\Delta \eta_{\mathrm{R}}, \Delta t$ and $\Delta w_{\mathrm{M}}$ are not known before self-propulsion factors in the trial condition are obtained. Therefore, the analysis described in this section is repeated after the value of $V_{\mathrm{S}}$ is obtained by the current analysis method described in Sect. 2. It is also noted that, for the initial value of the above evaluation, the mean value of $V_{\mathrm{G}}$ for one double run or the 'MoM' value of $V_{\mathrm{G}}$ for two double runs is used and the values of $\Delta \eta_{\mathrm{R}}, \Delta t$ and $\Delta w_{\mathrm{M}}$ are set to zero.

\section{Verification}

ITTC has been requested by MEPC 66 [66] to investigate and verify the accuracy of the 'Iterative' method, which is one of the choices in ISO 15016:2015 [15] 'Guidelines for the assessment of speed and power performance by analysis of speed trial data'. The alternative is the 'MoM' method proposed by ITTC, where for one power setting two double runs have to be performed. The verification of the 'Iterative' method is performed by members of ITTC's Specialist Committee coming from three independent towing tank institutes, SVA Vienna, HSVA and SSPA.

\subsection{Description of the verification}

Two current correction methods and two power correction methods have been evaluated, with the assumption that the added resistance is known. The study includes (Fig. 1):

- Iterative method-ISO15016:2015 [15]

- Means of Means method-ITTC 7.5-04-01-01.2 [12]

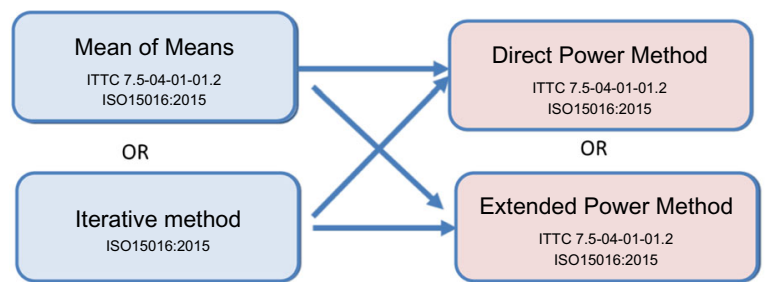

Fig. 1 Four combinations included in the study

- Direct power method-ITTC 7.5-04-01-01.2 [12]

- Extended power method of Annex K ISO15016:2015 [15]

The verification of the current correction is achieved by fabricated cases using model test performance predictions, which for all considered ship types were available, and for selected areas with known current profiles over the time, to know the 'true answers'.

For a given power setting to the corresponding speed received by the performance prediction the current speed of the respective current profile at the time of the particular run was added/subtracted. The received values were taken as the 'should have been measured' values and as the input for the current correction methods (Fig. 2, speed over the ground, shaft power, shaft speed). The application of the 'MoM' method and the 'Iterative' method gives the result for each method and the difference between the 'true values' and the respective result shows the accuracy of the applied method.

The threshold for an acceptable difference between 'true value' and calculated value of speed through the water is taken as in the ISO 15016:2015 [15] as $\Delta \mathrm{VS} \leq 0.10$ knots.

\subsection{Ship types}

The range of the typical time between the speed runs during the speed trial should cover the time span between half an hour and $2 \mathrm{~h}$ for the chosen ship types. Important criteria was also that the required model tests were available. The ship types investigated in this paper are listed in Table 1.

\subsection{Number of runs}

The number of runs was decided according to the new ISO 15016 standard taking into account the respective correction method for the current. Also, the cases for sister ships were investigated. Below are the number of runs and the power settings for the different cases. 
Fig. 2 Image of the fabricated $\mathrm{S} / \mathrm{T}$ data

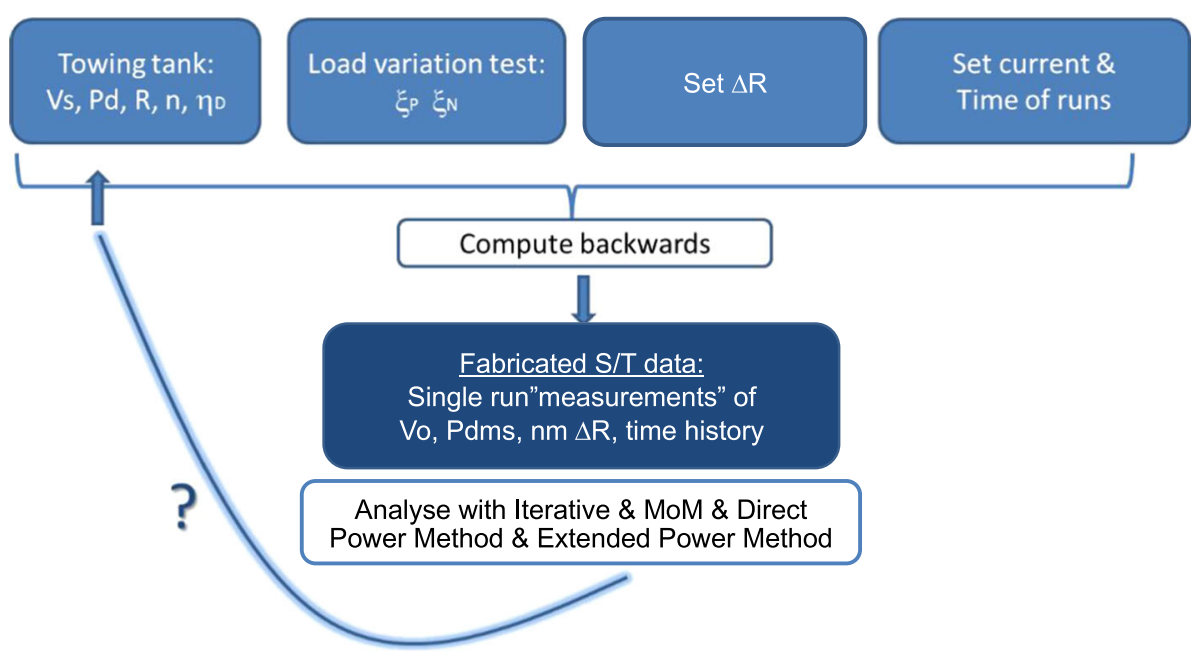

Table 1 Ship types

\begin{tabular}{llll}
\hline Ship type & $L_{\mathrm{PP}(\mathrm{m})}$ & Speed (knots) & Comments \\
\hline LNG & 280 & 19.5 & Large bulb effect \\
Small tanker & 165 & 14.0 & \\
Large container & 340 & 25.0 & $14,000 \mathrm{TEU}$ \\
Small container & 195 & 22.5 & $2,500 \mathrm{TEU}$ \\
VLCC & 320 & 15.1 & $350,000 \mathrm{t}$ \\
Cruise liner & 315.5 & 20.7 & $78,000 \mathrm{t}$ \\
\hline
\end{tabular}

\subsubsection{Iterative method}

- 1 double run at $50 \% \mathrm{MCR}$

- 1 or two double runs at $75 \%$ MCR (EEDI)

- 1 double run at 85 or $90 \%$ MCR (contract)

\subsubsection{Sistership case}

- 1 double run at $50 \% \mathrm{MCR}$

- 1 double run at $75 \%$ MCR (EEDI)

- 1 double run at 85 or $90 \%$ MCR

\subsection{3 'Mean of means' method}

- 1 double run at $50 \% \mathrm{MCR}$

- 2 double runs at $75 \%$ MCR (EEDI)

- 2 double runs at 85 or $90 \%$ MCR (contract)

\subsubsection{Sistership case (current speed $<0.2$ knots)}

- 1 double run at $50 \%$ MCR

- 1 double run at $75 \%$ MCR (EEDI)

- 1 double run at 85 or $90 \%$ MCR

\subsection{Current profiles}

The criteria for the choice of the current profiles was that they should not be too simple (just sinusoidal or parabolic) but rather realistic with time and maximum current speed. Figure 3 shows the current profiles over the time chosen and applied in this paper.

\subsection{Time span and starting time}

The starting time of the set of speed runs was varied with relation to the time of the current profiles (time lag). For the time span between the speed runs a typical time for the respective ship type was used. Also, a random variation of maximum $25 \%$ between the time spans has been applied.

\section{Results and discussion}

The calculation was performed by the spreadsheets which have been developed by the ISO (about 1,000 cases) and by an individually developed code which follows exactly ISO 15016:2015 [15] draft (more than 3,000 cases). It is noted that although the 'Extended Power Method' has some advantages, the verification results by the 'Direct Power Method' are mainly shown here because the 'Extended Power Method' is treated as an informative in ISO15016:2015 [15]

5.1 Examples of the calculations by using the spreadsheets

\subsubsection{Containership 14,000 TEU in Current Profile around Japan}

Table 2 shows the result of a containership 14,000 TEU in the current profile around Japan. The marked cells in the 

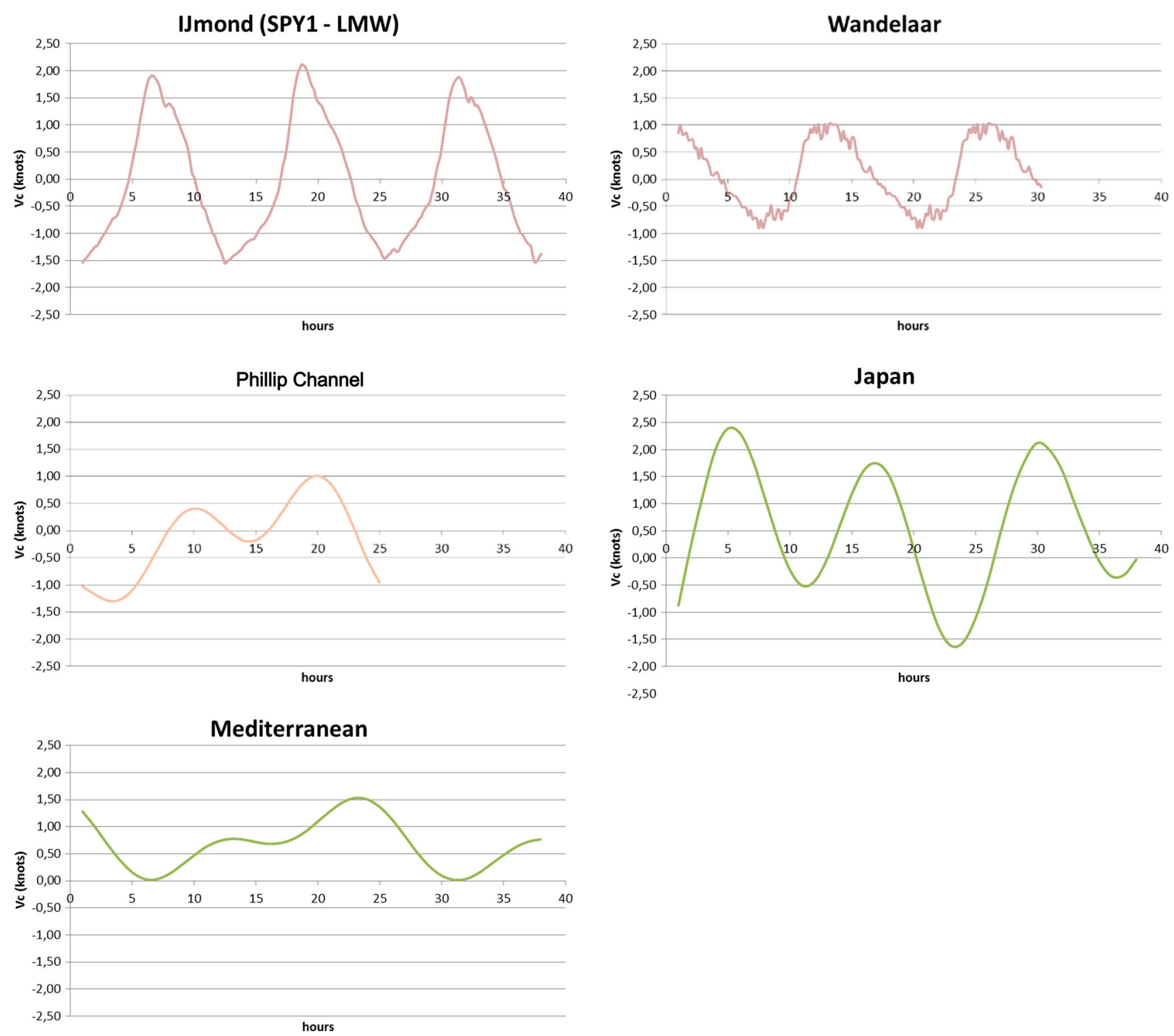

Fig. 3 Current profiles

two last columns at the right hand side of the table show when an error of an individual power setting exceeds the threshold of 0.1 knot. We note that large errors appear for the 'MoM' method for the first power setting in each data set. This is where only 1 double run has been performed. In a real sea trail, a curve will be fitted through the three points, which will smear out the error of the first point, so that the total error is reduced.

\subsubsection{VLCC 350,000 $t$ in current profile around Japan}

Table 3 shows the result of a VLCC 350,000 $t$ in the current profile around Japan, and Table 4 shows the result of the same ship with random variation of the time step. Comparison of the calculations with and without random

variation of the time steps shows, that the 'MoM' method becomes more accurate if the time steps between the runs of one power setting are as equal as possible.

Figure 4 shows an example how the 'Iterative' method approximates the current speed. The variation of the time steps has no influence on the result. The approximation can only be received after all runs of all power settings have been measured.

\subsubsection{Sister ships of VLCC 350,000 t in current profile around Japan}

Table 5 shows the results when only three double runs are performed $(1+1+1)$. This is the case foreseen in ISO 15016 for sister ships. 
Table 2 Containership 14,000 TEU in Japanese current profile

\begin{tabular}{|c|c|c|c|c|c|c|c|c|c|c|c|c|c|c|}
\hline & \multirow[t]{2}{*}{ Current } & \multirow{2}{*}{$\begin{array}{l}\text { Engine } \\
\text { load } \\
(\%)\end{array}$} & \multirow{2}{*}{$\begin{array}{l}\text { Time } \\
\text { lag } \\
\text { (h) }\end{array}$} & \multicolumn{2}{|c|}{$\begin{array}{l}\text { Time step } \\
(\min )\end{array}$} & \multirow[t]{2}{*}{$\begin{array}{l}\text { Double } \\
\text { runs }\end{array}$} & \multirow{2}{*}{$\begin{array}{l}\text { Speed } \\
\text { actual } \\
\text { (knots) }\end{array}$} & \multicolumn{2}{|c|}{$\begin{array}{l}\text { Current } \\
\text { (knots) }\end{array}$} & \multirow{2}{*}{$\begin{array}{l}\text { Current } \\
\text { variation } \\
\text { (knots) }\end{array}$} & \multicolumn{2}{|c|}{ Speed (knots) } & \multicolumn{2}{|c|}{ Error (knots) } \\
\hline & & & & Const. & Rand. & & & Up & Down & & MoM & It.M. & $\mathrm{MoM}$ & It.M. \\
\hline & & & & & & & & & & & & & 0.00 & 0.00 \\
\hline $14,000 \mathrm{TEU}$ & Japan & 65 & 0 & 60 & - & 1 & 22.72 & -0.68 & 0.34 & 1.02 & 22.24 & 22.74 & -0.48 & 0.02 \\
\hline $14,000 \mathrm{TEU}$ & Japan & 75 & 0 & 50 & - & 2 & 23.73 & 1.28 & 1.71 & 0.43 & 23.73 & 23.72 & 0.00 & -0.01 \\
\hline 14,000 TEL & Japan & 90 & 0 & 50 & - & 2 & 25.03 & 0.95 & -1.61 & -2.56 & 25.00 & 25.03 & -0.03 & 0.00 \\
\hline 14,000TEJ & Japan & 65 & 2 & 50 & - & 1 & 22.72 & 1.28 & 1.91 & 0.63 & 22.42 & 22.74 & -0.30 & 0.02 \\
\hline 14,000TEJ & Japan & 75 & 2 & 50 & - & 2 & 23.73 & 2.06 & -0.02 & -2.08 & 23.71 & 23.72 & -0.02 & -0.01 \\
\hline $14,000 \mathrm{TEU}$ & Japan & 90 & 2 & 60 & - & 2 & 25.03 & -0.96 & -1.53 & -0.57 & 25.02 & 25.03 & -0.01 & 0.00 \\
\hline $14,000 \mathrm{TEU}$ & Japan & 65 & 4 & 50 & - & 1 & 22.72 & 2.06 & 1.71 & -0.35 & 22.89 & 22.74 & 0.17 & 0.02 \\
\hline $14,000 \mathrm{TEU}$ & Japan & 75 & 4 & 60 & - & 2 & 23.73 & 0.95 & -1.61 & -2.56 & 23.70 & 23.72 & -0.03 & -0.01 \\
\hline $14,000 \mathrm{TEU}$ & Japan & 90 & 4 & 60 & - & 2 & 25.03 & -1.82 & 0.15 & 1.97 & 25.05 & 25.03 & 0.02 & 0.00 \\
\hline $14,000 \mathrm{TEU}$ & Japan & 65 & 6 & 50 & - & 1 & 22.72 & 0.95 & -0.02 & -0.97 & 23.18 & 22.74 & 0.46 & 0.02 \\
\hline $14,000 \mathrm{TEU}$ & Japan & 75 & 6 & 60 & - & 2 & 23.73 & -0.96 & -1.53 & -0.57 & 23.72 & 23.72 & -0.01 & -0.01 \\
\hline $14,000 \mathrm{TEU}$ & Japan & 90 & 6 & 60 & - & 2 & 25.03 & -0.81 & 1.83 & 2.64 & 25.06 & 25.03 & 0.03 & 0.00 \\
\hline $14,000 \mathrm{TEU}$ & Japan & 65 & 8 & 60 & - & 1 & 22.72 & -0.96 & -1.61 & -0.65 & 23.03 & 22.74 & 0.31 & 0.02 \\
\hline $14,000 \mathrm{TEU}$ & Japan & 75 & 8 & 60 & - & 2 & 23.73 & -1.82 & 0.15 & 1.97 & 23.75 & 23.72 & 0.02 & -0.01 \\
\hline $14,000 \mathrm{TEU}$ & Japan & 90 & 8 & 60 & - & 2 & 25.03 & 1.11 & 1.91 & 0.80 & 25.03 & 25.03 & 0.00 & 0.00 \\
\hline $14,000 \mathrm{TEU}$ & Japan & 65 & 10 & 60 & - & 1 & 22.72 & -1.82 & -1.53 & 0.29 & 22.58 & 22.74 & -0.14 & 0.02 \\
\hline $14,000 \mathrm{TEU}$ & Japan & 75 & 10 & 60 & - & 2 & 23.73 & -0.81 & 1.83 & 2.64 & 23.76 & 23.72 & 0.03 & -0.01 \\
\hline \multirow[t]{2}{*}{$14,000 \mathrm{TEU}$} & Japan & 90 & 10 & 60 & - & 2 & 25.03 & 2.12 & 0.34 & -1.78 & 25.01 & 25.04 & -0.02 & 0.01 \\
\hline & & & & & & & & & & & & & 0.00 & 0.00 \\
\hline
\end{tabular}

Table 3 VLCC 350,000 $\mathrm{t}$ in Japanese current profile without variation of the time steps

\begin{tabular}{|c|c|c|c|c|c|c|c|c|c|c|c|c|c|c|}
\hline & \multirow[t]{2}{*}{ Current } & \multirow{2}{*}{$\begin{array}{l}\text { Engine } \\
\text { load } \\
(\%)\end{array}$} & \multirow{2}{*}{$\begin{array}{l}\text { Time } \\
\text { lag } \\
\text { (h) }\end{array}$} & \multicolumn{2}{|c|}{$\begin{array}{l}\text { Time step } \\
\text { (min) }\end{array}$} & \multirow[t]{2}{*}{$\begin{array}{l}\text { Double } \\
\text { runs }\end{array}$} & \multirow{2}{*}{$\begin{array}{l}\text { Speed } \\
\text { actual } \\
\text { (knots) }\end{array}$} & \multicolumn{2}{|c|}{$\begin{array}{l}\text { Current } \\
\text { (knots) }\end{array}$} & \multirow{2}{*}{$\begin{array}{l}\text { Current } \\
\text { variation } \\
\text { (knots) }\end{array}$} & \multicolumn{2}{|c|}{ Speed (knots) } & \multicolumn{2}{|c|}{ Error (knots) } \\
\hline & & & & Const. & Rand. & & & Up & Down & & MoM & It.M. & MoM & It.M. \\
\hline 320,000 VLCC & Japan & 65 & 0 & 45 & & 1 & 13.62 & 0.81 & 1.59 & 0.78 & 13.41 & 13.62 & -0.21 & 0.00 \\
\hline 320,000 VLCC & Japan & 75 & 0 & 45 & - & 2 & 14.28 & 1.05 & -1.08 & -2.13 & 14.28 & 14.26 & 0.00 & -0.02 \\
\hline 320,000 VLCC & Japan & 90 & 0 & 45 & - & 2 & 15.16 & 1.31 & -0.72 & -2.03 & 15.15 & 15.16 & -0.01 & 0.00 \\
\hline $320,000 \mathrm{VLCC}$ & Japan & 65 & 3 & 45 & - & 1 & 13.62 & 1.47 & 0.48 & -0.99 & 13.77 & 13.62 & 0.15 & 0.00 \\
\hline 320,000 VLCC & Japan & 75 & 3 & 45 & - & 2 & 14.28 & -1.20 & 0.54 & 1.74 & 14.27 & 14.28 & -0.01 & 0.00 \\
\hline 320,000 VLCC & Japan & 90 & 3 & 45 & - & 2 & 15.16 & 0.99 & -1.26 & -2.25 & 15.16 & 15.16 & 0.00 & 0.00 \\
\hline 320,000 VLCC & Japan & 65 & 6 & 45 & - & 1 & 13.62 & -0.15 & -1.08 & -0.93 & 13.83 & 13.62 & 0.21 & 0.00 \\
\hline 320,000 VLCC & Japan & 75 & 6 & 45 & - & 2 & 14.28 & -1.02 & 0.78 & 1.80 & 14.28 & 14.29 & 0.00 & 0.01 \\
\hline 320,000 VLCC & Japan & 90 & 6 & 45 & - & 2 & 15.16 & -1.17 & 0.11 & 1.28 & 15.17 & 15.15 & 0.01 & -0.01 \\
\hline 320,000 VLCC & Japan & 65 & 9 & 45 & - & 1 & 13.62 & -1.20 & -0.60 & 0.60 & 13.57 & 13.62 & -0.05 & 0.00 \\
\hline 320,000 VLCC & Japan & 75 & 9 & 45 & - & 2 & 14.28 & 0.99 & -0.66 & -1.65 & 14.30 & 14.28 & 0.02 & 0.00 \\
\hline 320,000 VLCC & Japan & 90 & 9 & 45 & - & 2 & 15.16 & -1.26 & 1.47 & 2.73 & 15.20 & 15.16 & 0.04 & 0.00 \\
\hline 320,000 VLCC & Japan & 65 & 12 & 45 & - & 1 & 13.62 & 0.00 & 0.90 & 0.90 & 13.41 & 13.62 & -0.21 & 0.00 \\
\hline 320,000 VLCC & Japan & 75 & 12 & 45 & - & 2 & 14.28 & 0.78 & -1.17 & -1.95 & 14.28 & 14.28 & 0.00 & 0.00 \\
\hline 320,000 VLCC & Japan & 90 & 12 & 45 & - & 2 & 15.16 & 1.05 & -0.15 & -1.20 & 15.15 & 15.16 & 0.00 & 0.00 \\
\hline 320,000 VLCC & Japan & 65 & 15 & 45 & - & 1 & 13.62 & 0.99 & 0.36 & -0.63 & 13.69 & 13.62 & 0.07 & 0.00 \\
\hline 320,000 VLCC & Japan & 75 & 15 & 45 & - & 2 & 14.28 & -0.56 & 1.35 & 2.01 & 14.04 & 14.28 & -0.24 & 0.00 \\
\hline 320,000 VLCC & Japan & 90 & 15 & 45 & - & 2 & 15.16 & 1.47 & -1.20 & -2.67 & 15.15 & 15.15 & -0.01 & -0.01 \\
\hline
\end{tabular}


The 'Iterative' method gives quite accurate results with one double run per power setting whereas the 'MoM' method again would require two double runs for each power setting to be reliable.

\subsubsection{VLCC 350,000 t in Ijmond and Wandelaar current profile}

Table 6 shows the results for the current distribution at Ijmond, where obviously both methods fail. Figure 5 shows the approximation by the 'Iterative' method for the current distribution at Ijmond. Both the 'MoM' and the 'Iterative' methods failed in many cases for the Wandelaar and Ijmond current distributions. These areas should be avoided for VLCC S/P trials.

Through the verifications, the following conclusions are also obtained. In the case of shorter time periods between the runs (up to $60 \mathrm{~min}$ ), the methods are equally adequate. In specific cases, the 'MoM' method has advantages over the 'Iterative' method: in cases where the speed-power

Table 4 VLCC 350,000 $\mathrm{t}$ in current profile around Japan with random variation of the time steps

\begin{tabular}{|c|c|c|c|c|c|c|c|c|c|c|c|c|c|c|}
\hline & \multirow[t]{2}{*}{ Current } & \multirow{2}{*}{$\begin{array}{l}\text { Engine } \\
\text { load } \\
(\%)\end{array}$} & \multirow{2}{*}{$\begin{array}{l}\text { Time } \\
\text { lag } \\
\text { (h) }\end{array}$} & \multicolumn{2}{|c|}{$\begin{array}{l}\text { Time step } \\
\text { (min) }\end{array}$} & \multirow[t]{2}{*}{$\begin{array}{l}\text { Double } \\
\text { runs }\end{array}$} & \multirow{2}{*}{$\begin{array}{l}\text { Speed } \\
\text { actual } \\
\text { (knots) }\end{array}$} & \multicolumn{2}{|c|}{$\begin{array}{l}\text { Current } \\
\text { (knots) }\end{array}$} & \multirow{2}{*}{$\begin{array}{l}\text { Current } \\
\text { variation } \\
\text { (knots) }\end{array}$} & \multicolumn{2}{|c|}{ Speed (knots) } & \multicolumn{2}{|c|}{ Error (knots) } \\
\hline & & & & Const. & Rand. & & & Up & Down & & MoM & It.M. & MoM & It.M. \\
\hline 320,000 VLCC & Japan & 65 & 0 & 120 & \pm 30 & 1 & 13.62 & -0.68 & 1.58 & -2.26 & 12.49 & 13.58 & -1.13 & -0.04 \\
\hline $320,000 \mathrm{VLCC}$ & Japan & 75 & 0 & 120 & \pm 30 & 2 & 14.28 & 0.94 & -1.20 & -2.14 & 14.00 & 14.28 & -0.28 & 0.00 \\
\hline 320,000 VLCC & Japan & 90 & 0 & 120 & \pm 30 & 2 & 15.16 & 0.66 & -1.05 & -1.71 & 15.16 & 15.18 & 0.00 & 0.02 \\
\hline 320,000 VLCC & Japan & 65 & 3 & 120 & \pm 30 & 1 & 13.62 & 1.91 & 1.46 & 0.45 & 13.85 & 13.59 & 0.23 & -0.03 \\
\hline 320,000 VLCC & Japan & 75 & 3 & 120 & \pm 30 & 2 & 14.28 & -0.10 & 0.95 & 1.05 & 14.48 & 14.28 & 0.20 & 0.00 \\
\hline 320,000 VLCC & Japan & 90 & 3 & 120 & \pm 30 & 2 & 15.16 & 0.68 & -0.83 & -1.51 & 15.06 & 15.20 & -0.10 & 0.04 \\
\hline 320,000 VLCC & Japan & 65 & 6 & 120 & \pm 30 & 1 & 13.62 & 0.95 & -1.26 & 2.21 & 14.73 & 13.64 & 1.11 & 0.02 \\
\hline 320,000 VLCC & Japan & 75 & 6 & 120 & \pm 30 & 2 & 14.28 & -0.95 & 0.39 & 1.34 & 14.58 & 14.28 & 0.30 & 0.00 \\
\hline 320,000 VLCC & Japan & 90 & 6 & 120 & \pm 30 & 2 & 15.16 & -0.79 & 0.96 & 1.75 & 15.13 & 15.15 & -0.03 & -0.01 \\
\hline 320,000 VLCC & Japan & 65 & 9 & 120 & \pm 30 & 1 & 13.62 & -1.61 & -1.29 & 0.32 & 13.46 & 13.64 & -0.16 & 0.02 \\
\hline 320,000 VLCC & Japan & 75 & 9 & 120 & \pm 30 & 2 & 14.28 & 0.63 & -1.15 & -1.78 & 14.11 & 14.28 & -0.17 & 0.00 \\
\hline $320,000 \mathrm{VLCC}$ & Japan & 90 & 9 & 120 & \pm 30 & 2 & 15.16 & -1.10 & 1.37 & 2.47 & 15.31 & 15.14 & 0.15 & -0.02 \\
\hline $320,000 \mathrm{VLCC}$ & Japan & 65 & 12 & 120 & \pm 30 & 1 & 13.62 & -0.81 & 1.43 & -2.24 & 12.30 & 13.37 & 1.12 & -0.05 \\
\hline $320,000 \mathrm{VLCC}$ & Japan & 75 & 12 & 120 & \pm 30 & 2 & 14.28 & 0.71 & -1.25 & -1.96 & 13.98 & 14.29 & -0.30 & 0.01 \\
\hline $320,000 \mathrm{VLCC}$ & Japan & 90 & 12 & 120 & \pm 30 & 2 & 15.16 & 1.59 & -0.51 & -2.10 & 15.17 & 15.22 & 0.01 & 0.06 \\
\hline $320,000 \mathrm{VLCC}$ & Japan & 65 & 15 & 120 & \pm 30 & 1 & 13.62 & 1.83 & 1.71 & 0.12 & 13.68 & 13.56 & 0.06 & -0.06 \\
\hline 320,000 VLCC & Japan & 75 & 15 & 120 & \pm 30 & 2 & 14.28 & -1.22 & 1.35 & 2.57 & 14.42 & 14.26 & 0.14 & -0.02 \\
\hline 320,000 VLCC & Japan & 90 & 15 & 120 & \pm 30 & 2 & 15.16 & 1.46 & -1.10 & -2.56 & 15.08 & 15.18 & 0.08 & 0.02 \\
\hline
\end{tabular}

Fig. 4 An example how the 'Iterative' method approximates the current speed

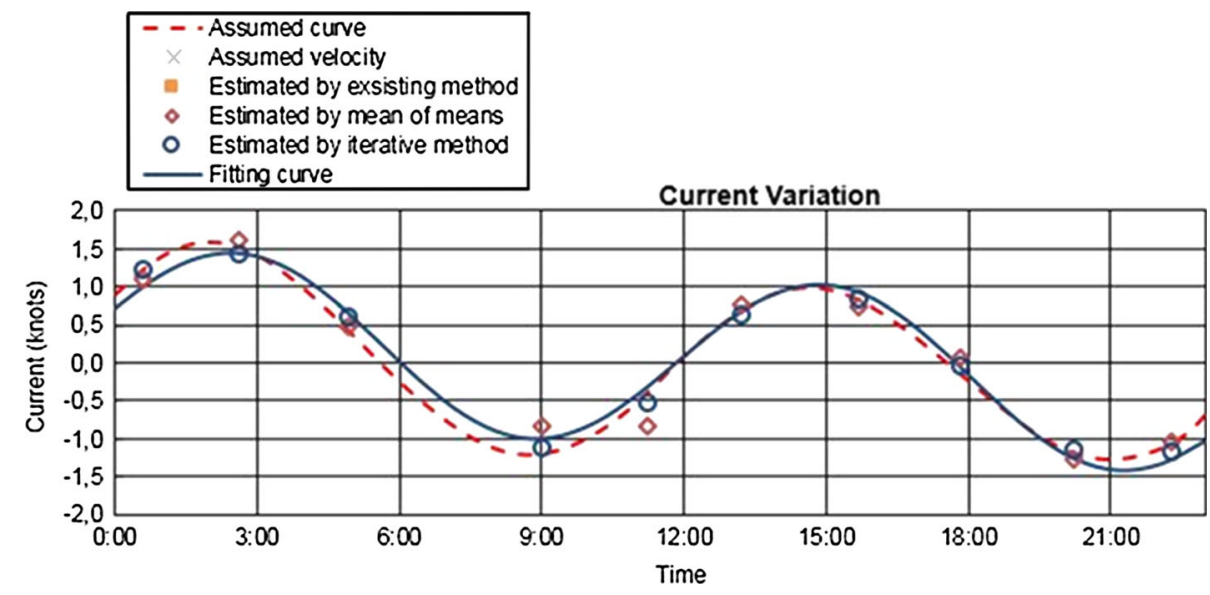


Table 5 Sister ships of VLCC 350,000 t in current profile around Japan

\begin{tabular}{|c|c|c|c|c|c|c|c|c|c|}
\hline & \multirow[t]{2}{*}{ Current } & \multirow[t]{2}{*}{ Engine load (\%) } & \multirow[t]{2}{*}{ Time lag (h) } & \multicolumn{2}{|c|}{ Time step (min) } & \multicolumn{2}{|c|}{ Speed 6run (min) } & \multicolumn{2}{|c|}{ Error 6run (min) } \\
\hline & & & & Const. & Rand. & M & It.M. & M & It.M \\
\hline $320,000 \mathrm{~V} 1 \mathrm{CC}$ & Japan & 65 & 0 & 120 & \pm 30 & 12.49 & 13.61 & -1.13 & -0.01 \\
\hline $320,000 \mathrm{VlCC}$ & Japan & 75 & 0 & 120 & \pm 30 & 15.13 & 14.29 & 0.85 & 0.01 \\
\hline $320,000 \mathrm{VlCC}$ & Japan & 90 & 0 & 120 & \pm 30 & 15.08 & 15.16 & -0.08 & 0.00 \\
\hline $320,000 \mathrm{~V} 1 \mathrm{CC}$ & Japan & 65 & 3 & 120 & \pm 30 & 13.85 & 13.61 & 0.23 & -0.01 \\
\hline $320,000 \mathrm{VLCC}$ & Japan & 75 & 3 & 120 & \pm 30 & 14.95 & 14.29 & 0.67 & 0.01 \\
\hline 320,000 VLCC & Japan & 90 & 3 & 120 & \pm 30 & 14.20 & 15.16 & -0.96 & 0.00 \\
\hline $320,000 \mathrm{~V} 1 \mathrm{CC}$ & Japan & 65 & 6 & 120 & \pm 30 & 14.73 & 13.63 & 1.11 & 0.01 \\
\hline 320,000 VLCC & Japan & 75 & 6 & 120 & \pm 30 & 13.47 & 14.27 & -0.81 & -0.01 \\
\hline $320,000 \mathrm{VLCC}$ & Japan & 90 & 6 & 120 & \pm 30 & 15.15 & 15.16 & -0.01 & 0.00 \\
\hline 320,000 VLCC & Japan & 65 & 9 & 120 & \pm 30 & 13.46 & 13.63 & -0.16 & 0.01 \\
\hline $320,000 \mathrm{VLCC}$ & Japan & 75 & 9 & 120 & \pm 30 & 13.54 & 14.27 & -0.74 & -0.01 \\
\hline $320,000 \mathrm{VLCC}$ & Japan & 90 & 9 & 120 & \pm 30 & 16.10 & 15.16 & 0.94 & 0.00 \\
\hline $320,000 \mathrm{VLCC}$ & Japan & 65 & 12 & 120 & \pm 30 & 12.50 & 13.61 & -1.12 & -0.01 \\
\hline 320,000 VLCC & Japan & 75 & 12 & 120 & \pm 30 & 15.02 & 14.29 & 0.74 & 0.01 \\
\hline 320,000 VLCC & Japan & 90 & 12 & 120 & \pm 30 & 15.24 & 15.16 & 0.08 & 0.00 \\
\hline $320,000 \mathrm{VLCC}$ & Japan & 65 & 15 & 120 & \pm 30 & 13.68 & 13.62 & 0.06 & 0.00 \\
\hline 320,000 VLCC & Japan & 75 & 15 & 120 & \pm 30 & 15.08 & 14.29 & 0.80 & 0.01 \\
\hline 320,000 VLCC & Japan & 90 & 15 & 120 & \pm 30 & 14.20 & 15.14 & -0.96 & -0.02 \\
\hline
\end{tabular}

Table 6 VLCC 350,000 $\mathrm{t}$ in Ijmond current profile

\begin{tabular}{|c|c|c|c|c|c|c|c|c|c|c|c|c|c|c|}
\hline & \multirow[t]{2}{*}{ Current } & \multirow{2}{*}{$\begin{array}{l}\text { Engine } \\
\text { load } \\
(\%)\end{array}$} & \multirow{2}{*}{$\begin{array}{l}\text { Time } \\
\text { lag } \\
\text { (h) }\end{array}$} & \multicolumn{2}{|c|}{$\begin{array}{l}\text { Time step } \\
\text { (min) }\end{array}$} & \multirow[t]{2}{*}{$\begin{array}{l}\text { Double } \\
\text { runs }\end{array}$} & \multirow{2}{*}{$\begin{array}{l}\text { Speed } \\
\text { actual } \\
\text { (knots) }\end{array}$} & \multicolumn{2}{|c|}{$\begin{array}{l}\text { Current } \\
\text { (knots) }\end{array}$} & \multirow{2}{*}{$\begin{array}{l}\text { Current } \\
\text { variation } \\
\text { (knots) }\end{array}$} & \multicolumn{2}{|c|}{ Speed (knots) } & \multicolumn{2}{|c|}{ Error (knots) } \\
\hline & & & & Const. & Rand. & & & Up & Down & & MoM & It.M. & MoM & It.M. \\
\hline 320,000 VLCC & Ijmond & 65 & 0 & 120 & \pm 30 & 1 & 13.62 & -1.24 & -0.29 & -0.95 & 13.15 & 13.69 & -0.47 & 0.07 \\
\hline 320,000 VLCC & Ijmond & 75 & 0 & 120 & \pm 30 & 2 & 14.28 & 1.81 & -0.82 & -2.63 & 14.03 & 14.43 & -0.25 & 0.15 \\
\hline 320,000 VLCC & Ijmond & 90 & 0 & 120 & \pm 30 & 2 & 15.16 & -1.35 & 1.44 & 2.79 & 15.65 & 15.41 & 0.49 & 0.25 \\
\hline 320,000 VLCC & Ijmond & 65 & 3 & 120 & \pm 30 & 1 & 13.62 & 0.30 & 1.69 & -1.38 & 12.93 & 13.44 & -0.69 & -0.18 \\
\hline 320,000 VLCC & Ijmond & 75 & 3 & 120 & \pm 30 & 2 & 14.28 & 1.43 & -1.42 & -2.85 & 14.39 & 14.39 & 0.11 & 0.11 \\
\hline 320,000 VLCC & Ijmond & 90 & 3 & 120 & \pm 30 & 2 & 15.16 & -0.37 & 2.10 & 2.47 & 15.13 & 15.40 & -0.03 & 0.24 \\
\hline 320,000 VLCC & Ijmond & 65 & 6 & 120 & \pm 30 & 1 & 13.62 & 1.39 & -0.26 & 1.65 & 14.45 & 13.43 & 0.83 & -0.19 \\
\hline 320,000 VLCC & Ijmond & 75 & 6 & 120 & \pm 30 & 2 & 14.28 & -1.45 & 0.31 & 1.76 & 14.31 & 14.12 & 0.03 & -0.16 \\
\hline 320,000 VLCC & Ijmond & 90 & 6 & 120 & \pm 30 & 2 & 15.16 & 1.69 & -1.27 & -2.96 & 15.10 & 15.07 & -0.06 & -0.09 \\
\hline 320,000 VLCC & Ijmond & 65 & 9 & 120 & \pm 30 & 1 & 13.62 & 0.03 & -1.40 & 1.43 & 14.34 & 13.73 & 0.72 & 0.11 \\
\hline 320,000 VLCC & Ijmond & 75 & 9 & 120 & \pm 30 & 2 & 14.28 & -1.36 & 1.85 & 3.21 & 14.88 & 14.47 & 0.60 & 0.19 \\
\hline 320,000 VLCC & Ijmond & 90 & 9 & 120 & \pm 30 & 2 & 15.16 & 0.05 & -1.05 & -1.10 & 15.24 & 15.30 & 0.08 & 0.14 \\
\hline 320,000 VLCC & Ijmond & 65 & 12 & 120 & \pm 30 & 1 & 13.62 & -1.45 & -0.93 & -0.53 & 13.36 & 13.65 & -0.26 & 0.03 \\
\hline 320,000 VLCC & Ijmond & 75 & 12 & 120 & \pm 30 & 2 & 14.28 & 2.05 & -0.83 & -2.88 & 14.05 & 14.30 & -0.23 & 0.02 \\
\hline 320,000 VLCC & Ijmond & 90 & 12 & 120 & \pm 30 & 2 & 15.16 & -1.32 & 1.44 & 2.76 & 15.10 & 15.28 & -0.06 & 0.12 \\
\hline 320,000 VLCC & Ijmond & 65 & 15 & 120 & \pm 30 & 1 & 13.62 & -0.69 & 1.91 & -2.61 & 12.32 & 13.29 & -1.30 & -0.33 \\
\hline 320,000 VLCC & Ijmond & 75 & 15 & 120 & \pm 30 & 2 & 14.28 & 1.71 & -1.05 & -2.76 & 14.11 & 14.07 & -0.17 & -0.21 \\
\hline 320,000 VLCC & Ijmond & 90 & 15 & 120 & \pm 30 & 2 & 15.16 & -0.15 & 1.79 & 1.94 & 14.93 & 14.91 & -0.23 & -0.25 \\
\hline
\end{tabular}


Fig. 5 The approximation by the 'Iterative' method for the current distribution at Ijmond
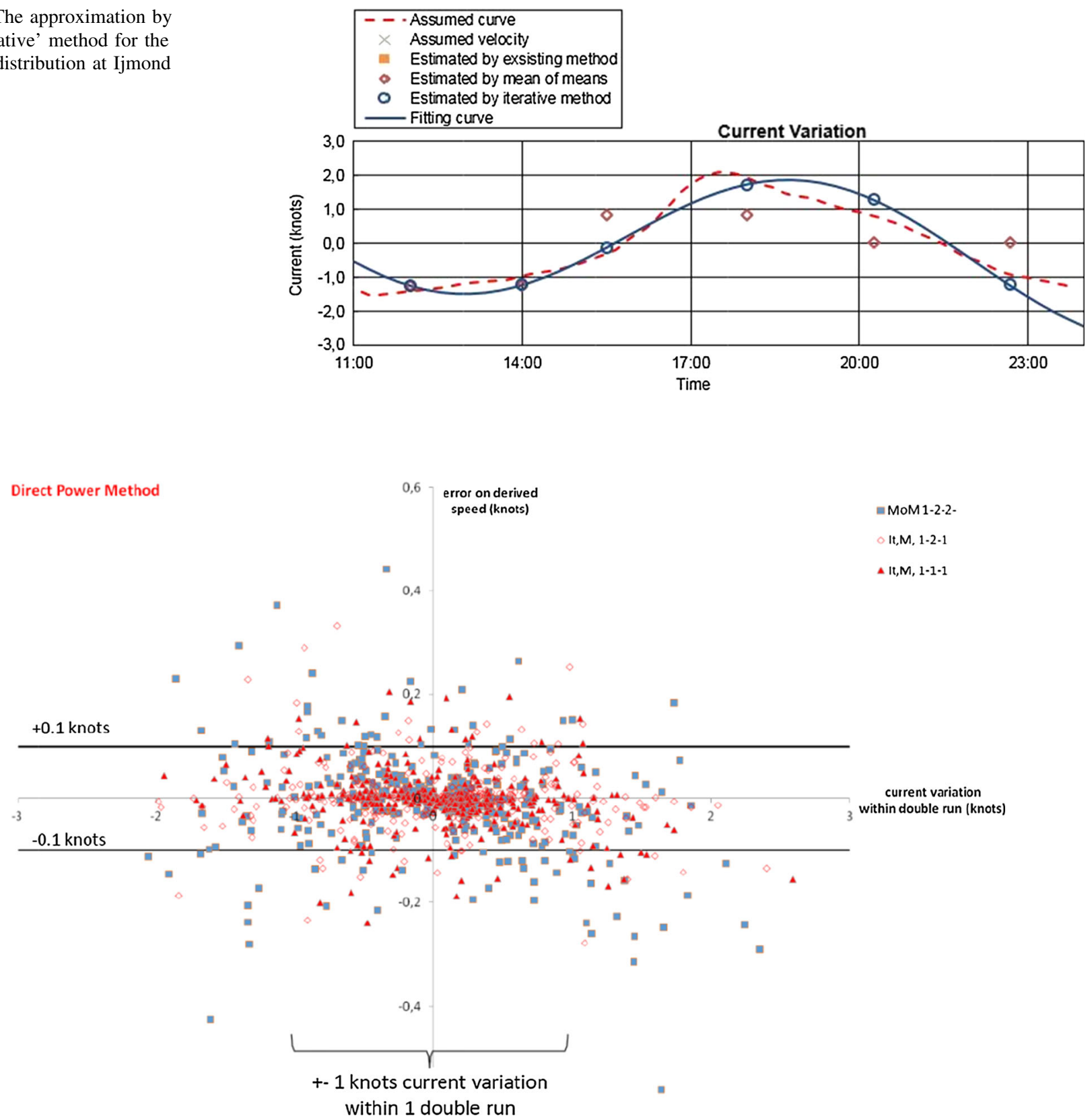

Fig. 6 The spreading of the results of the two methods

curve deviates significantly from the assumed power function $\left(a+b V_{\mathrm{p}}\right)$, e.g. in case of large speed range and/or humps and hollows within the curve.

\subsection{Statistical approach}

An independently developed verification code was used in conjunction to the spreadsheets provided by the ISO group. In this approach the error was extracted from the faired speed-power curve, as in a real sea trial, and not taken for each individual power setting, as in the mentioned spreadsheets. A large number of test cases made a statistical evaluation of the error possible. Figure 6 shows the spreading of the results of the two methods, where all red points represent the 'Iterative' and the blue points the 'MoM' method. From the mean and the variance of this, a normal distribution can be derived as shown in Fig. 7. Figure 7 shows that both methods are adequate if for the 'MoM' method at each power setting two double runs are performed (dotted blue line represents the 'MoM' method with $1+2+2$ double runs). 


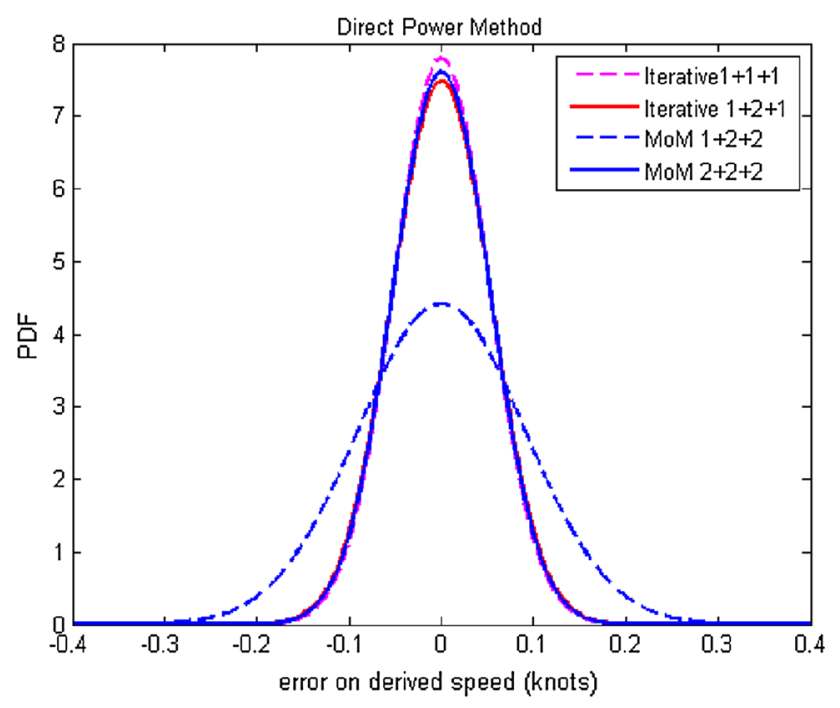

Fig. 7 Probability distribution of the error on derived speed

\section{Conclusions}

The following concluding remarks have been obtained through the present verification study.

1. Using the 'MoM' method for each power setting, two double runs $(2+2+2$ double runs) should be made to keep the accuracy of S/P trials.

2. In general the 'Iterative' method leads to less errors in average of the tested cases when $1+2+2$ double runs are used in the 'MoM' method.

3. In the case of shorter time periods between the runs (up to $60 \mathrm{~min}$ ) the methods are equally adequate.

4. In specific cases, the 'MoM' method has advantages over the 'Iterative' method: in cases where the speedpower curve deviates significantly from the assumed power function $\left(a+b V_{\mathrm{p}}\right)$, e.g. in case of large speed range and/or humps and hollows within the curve.

5. In case of current time history deviating from the assumed parabolic/sinusoidal trend and the change of the current within the time span of two double runs is very high, neither of the methods are applicable. These areas, when known, should be avoided.

6. The 'Iterative' method is fully compatible with the 'Simple Direct Power Method' which is shown in ITTC Recommended Procedure 7.5-04-01-01.2 [12].
Acknowledgments Authors are grateful to all experts of ISO/TC8/ SC6/WG17 and ITTC/PSS for their valuable discussions. Authors also appreciate very much Ms. Eriko Nishimura for her devoted cooperation as the secretary of ISO/TC8/SC6/WG17.

Open Access This article is distributed under the terms of the Creative Commons Attribution License which permits any use, distribution, and reproduction in any medium, provided the original author(s) and the source are credited.

\section{References}

1. ISO15016 (2002) Guidelines for the assessment of speed and power performance by analysis of speed trial data

2. International Towing Tank Conference (1969) ITTC guide for measured-mile trials, Report of the Performance Committee. In: Proceedings of 12th ITTC, Appendix I, Rome, Italy, pp 194-197

3. International Towing Tank Conference (1996) An updated guide for speed/powering trials, Powering Performance Committee Report. In: Proceedings of 21st ITTC, vol 1, Appendix I, Trondheim, Norway

4. Society of Naval Architects and Marine Engineers Technical and Research Program (1973) Panel M-19 (Ship Trials), Technical \& Research Code C2 'Code for Sea Trials 1973', SNAME

5. Society of Naval Architects and Marine Engineers Ship's Machinery Committee (1989) Panel M-19 (Ship Trials), 1989, Technical \& Research Bulletin 3-47 'Guide for Sea Trials 1989', SNAME

6. BSRA (1978) BSRA standard method of speed trial analysis, BSRA Report NS 466

7. Sea Trial Analysis JIP (2006) Recommended practice for speed trials, public document from http://www.marin.nl

8. The Specialist Committee on Trials and Monitoring (1999) Final Report and Recommendations to the 22nd ITTC. The Proc. of the 22nd ITTC, vol II

9. The Specialist Committee on Speed and Powering Trials (2002) Final Report and Recommendations to the 23rd ITTC. The Proc. of the 23rd ITTC, vol II

10. Norway (2011) Verification of the EEDI and comments on ISO 15016:2002 and the equivalent methods for performing sea trials, MEPC 62/5/5

11. Report of the Marine Environment Protection Committee on its Sixty-third Session (2012) MEPC 63/23

12. ITTC (2012) Additional information on ITTC recommended procedure 7.5-04-01-01.2, 'Speed/power trials, part 2, analysis of speed/power trial data', MEPC 64/INF.6

13. ITTC (2013) ITTC recommended procedure 7.5-04-01-01.1 speed and power trials, part 1, preparation and conduct, MEPC 65/INF.7

14. Report of the Marine Environment Protection Committee on its Sixty-fifth Session (2013) MEPC 65/22

15. ISO15016 (2015) Guidelines for the Assessment of Speed and Power Performance by Analysis of Speed Trial Data

16. Report of the Marine Environment Protection Committee on its Sixty-third Session (2014) MEPC 66/21 